\title{
An integrative framework for salamander and mouse limb regeneration
}

\author{
DUYGU PAYZIN-DOGRU ${ }^{1}$ and JESSICA L. WHITED*1,2 \\ ${ }^{1}$ Harvard Medical School, the Harvard Stem Cell Institute, and Brigham \& Women's Hospital, Department of \\ Orthopedic Surgery, Boston, MA and ${ }^{2}$ The Allen Discovery Center at Tufts Univesity, Medford, MA, USA
}

\begin{abstract}
Appendage regeneration is not a simple task. The animal must harness all of its energy and resources to orchestrate perhaps one of the most complicated events since its development. Balancing the immune response, wound healing, proliferation, patterning and differentiation is an elegant job, and how some animals achieve that still leaves researchers enchanted today. In this work, we review some of the molecular aspects of regeneration, with a focus on the axolotl, the champion of tetrapod limb regeneration, and the mouse, an excellent mammalian model for digit tip regeneration. Advances in molecular and genomic tools have enabled the discovery of exciting fundamental features of limb regeneration. Integrating the data from different animal systems will be crucial to understanding the common requirements of successful appendage regeneration and places for flexibility. The combination of these efforts is paving the way to grasping how good regenerators respond to the loss of body parts, how these mechanisms might compare in modest regenerators, and, ultimately, in developing approaches for improving regenerative outcomes in humans.
\end{abstract}

KEY WORDS: limb regeneration, digit tip regeneration, axolotl

\section{Organisms have varying regenerative abilities}

Regeneration of body parts is one of the most intriguing events in biology. Scientists have been mystified for centuries to understand why organisms vary greatly in their ability to regenerate lost body parts. On one end of the spectrum are invertebrates, which are superb regenerators. Hydra and planarians can regenerate a full organism from only a very small body fragment, and this capacity seems to be infinite (Dalyell, 1814, Morgan, 1901, Pallas and Pauli, 1780). Among vertebrates, salamanders have extensive regenerative capabilities (Spallanzani, 1769). Axolotls can regenerate a number of their organs and tissues, such as the tail, limbs, and spinal cord (Goss, 1969, Odelberg, 2005). Importantly, most of these capabilities are preserved in the adult (Brockes and Kumar, 2005, Yun, 2015). Conversely, frogs can only achieve perfect regeneration as tadpoles, when limb development is ongoing (Dent, 1962, Muneoka et al., 1986, Sessions and Bryant, 1988, Tseng and Levin, 2008). On the opposite end of the spectrum are mammals, with relatively limited appendage regeneration abilities. Mice and humans can only regenerate their digit tips, and in humans, children appear to be more successful than adults (Borgens, 1982, Douglas, 1972, Illingworth, 1974). Although restricted, the pres- ence of such regenerative capabilities hints at potentially dormant mechanisms that might be leveraged if we can fully understand how limb regeneration operates.

\section{Overview of limb regeneration in salamanders}

Much of the knowledge of limb regeneration comes from salamanders, especially newts and axolotls. Both newts and axolotls are urodele amphibians, but their 150 million years of evolutionary divergence makes the conservation of their regenerative abilities remarkable (Zhang and Wake, 2009). Numerous species of newt are used to study limb regeneration, such as the eastern newt (Notophthalmus viridescens), the red-spotted newt (Triturus viridescens) and the Iberian ribbed newt (Pleurodeles walt'). Herein, newt refers to Notophthalmus viridescens, and axolotl refers to Ambystoma mexicanum.

The outward hallmarks of limb regeneration proceed in a ste-

Abbreviations used in this paper: AEC, apical epidermal cap; BMP, bone morphogenetic protein; EGF, epidermal growth factor; FGF. fibroblast growth factor; msx 1, muscle segment homeobox 1;TGF-beta, transforming growth factor beta; WE, wound epidermis; Wnt, wingless-related integration site.

\footnotetext{
*Address correspondence to: Jessica Whited. Brigham \& Women's Hospital, Department of Orthopedic Surgery, 60 Fenwood Rd., 7016D, Boston, MA, USA. Tel: +1(857) 307-5484. Fax: +1(857) 307-0300. E-mail: jwhited@ bwh.harvard.edu - (iD) http://orcid.org/0000-0002-3709-6515
} 
reotypical fashion and move from immediate wound healing to orchestrated growth and then to resolution and return to homeostasis (reviewed in (Tanaka, 2016)). Upon amputation of the axolotl limb, a blood clot quickly clogs the cut site. Within a day, a special layer of epithelial cells covers the surface of the wound, forming the wound epidermis (WE). The cells in the wound epidermis proliferate and give rise to a structure called the apical epidermal cap (AEC). The $A E C$ is thought to supply many of the essential signals necessary to instruct the formation of a conical shaped outgrowth underneath it. This structure, called the blastema, is composed of the cells that will eventually form the regenerated limb (Fig. 1).

Following successful blastema formation, cells proliferate to expand the progenitor pool, and cellular differentiation and limb re-patterning occurs. An important question that deserves more attention is whether there exists a blastema "checkpoint" for determining when the blastema has grown large enough to progress into later stages and, if so, how the checkpoint might operate at a molecular level. Nonetheless, once it has grown a certain size, which appears to require various amounts of time based on the starting size of the limb, the blastema flattens and takes a shape similar to the growing limb during normal development. From this point on, many of the events that take place appear to be similar to those in limb development. At this phase, the most noteworthy difference between regeneration and normal limb development is the scale of events. The amount of new tissue formed during regeneration is significantly more than that in limb development, which happens when the salamander is only a larva. Furthermore, in regeneration, mature vasculature and nerves in the proximal stump must integrate with newly-formed networks in the regenerate limb.

\section{Mouse digit tip: the mammalian limb regeneration model}

Mice can only regenerate the tip of their digits, the region that is distal of the third phalangeal element. They can do so at any stage in life, as embryos, neonates, and adults (Borgens, 1982,
Han et al., 2008, Neufeld and Zhao, 1995, Reginelli et al., 1995). Intriguingly, more proximal aspects of the digit can undergo regeneration in embryonic mouse digits compared to post-natal mouse digits. Furthermore, post-natally, digit tip regeneration is dependent upon presence of the nail bed (Zhao and Neufeld, 1995). The main stages of the regeneration process are similar to that of the axolotl limb regeneration. First, the amputation surface is closed by the wound epidermis. Next, a pool of progenitor cells forms into a blastema underneath the wound epidermis, where they proliferate. Finally, the blastema cells re-differentiate to give rise to a new digit tip. Nevertheless, the features of each stage are slightly different, which makes it a very useful model to understand the limitations of mammalian regeneration. For example, wound healing in response to amputation is a much slower process in mice. (Fernando et al., 2011, Han et al., 2008). An experimentally-applied wound dressing can permit a hypoxic environment and allow a quicker epidermal closure (Simkin et al., 2015). Without a wound dressing, the epidermal cells cannot fully cover the amputated bone, and undergo a histolysis stage, where osteoclasts breakdown some of the bone at the stump, and the wound epidermis crawls over the generated space (Fernando et al., 2011). In this case, regeneration begins proximal to the amputation site. Therefore, a wound dressing enables the regenerate to more closely recapitulate the amputated structure (Simkin et al., 2015). The timing of wound closure and blastema formation is variable, and takes 8-12 days following amputation of adult mice digit tips (Fernando et al., 2011). Though the entire morphological pattern of the digit tip is correctly re-established, the edges of regenerate skeleton are less-than-perfectly smooth, indicating there may be differences not yet understood. Furthermore, one report indicates that regenerated digit tips can be slightly shorter than unamputated digit tips (Han et al., 2008), though this observation warrants further investigation. This less-than-perfect, epimorphic regeneration has led some to speculate digit tip regeneration may have evolved from a non-regenerative state, and might provide

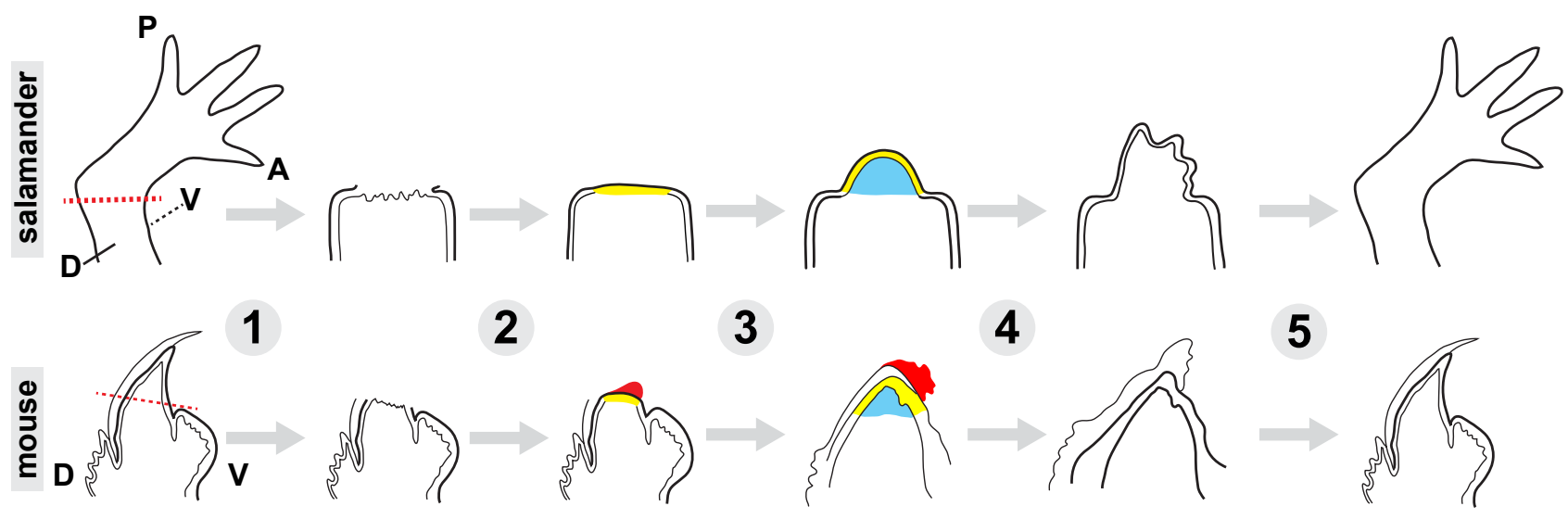

Fig. 1. Overview of events during salamander limb regeneration and mouse digit tip regeneration. (1) Following amputation (red dotted line), a raw surface is apparent in both salamanders and mice. (2) A wound epidermis (yellow) forms by migration, and then proliferation, of epidermal cells from the stump. Note that a blood clot (red) is usually visually apparent in the mouse at this time point, while in salamanders, it typically falls off within minutes or hours. (3) Mesenchymal progenitor cells from within the stump are activated and recruited to form the blastema (blue), beneath the wound epidermis. (4) Differentiation occurs, producing the full repertoire of internal tissues from blastema cells and a mature epidermis from wound epidermis. (5) Growth, patterning, and reconnection of blood vessels and nerves ensures an exact replica forms to replace the lost limb or digit tip. Note the plane of sectioning in salamander limbs versus mouse digit tips; both are depicted through the central-most section of the structure, but the salamander limb is face-view and the mouse digit tip is side-view ( $D$, dorsal; $V$, ventral; P, posterior; $A$, anterior). 
us with important clues about why mammalians are more limited in their regenerative capabilities (Muneoka et al., 2008). One study uncovering such limitations discovered the role of the bone morphogenic protein (BMP) pathway in digit tip regeneration. Implanting BMP2- or BMP7-soaked beads underneath the wound epidermis was found to impart regeneration potential to neonatal mice with proximal amputations that would not normally regenerate (Yu et al., 2010). This experiment demonstrates that application of external factors might improve regenerative success in otherwise non-permissive environments.

\section{Early post-injury events and wound healing}

In axolotls, following amputation, cells throughout the amputated limb and even in distant locations, such as the contralateral limb, are stimulated to re-enter the cell cycle (Johnson et al., 2018). The role of systemic activation following amputation and other injuries in axolotls is currently unclear. Future work will be required to understand how this activation relates to localized tissue growth and blastema formation, though parallels to the activation that occurs in other species are tangible. For example, in planarians, neoblasts initially become activated throughout the body, and later their activity is localized to the amputation site (Wenemoser and Reddien, 2010). Mice show a parallel systemic cell cycle re-entry response to injuries (Rodgers et al., 2014), though this response has not yet been examined following amputation, and its possible relationship to digit tip regeneration is completely unknown.

Successful formation of the wound epidermis at the site of injury is essential to limb regeneration. Preventing the formation of the wound epithelium by placing the amputated limb into the body cavity results in regenerative failure, resulting only in some amorphous cartilage formation (Goss, 1956a). Importantly, if the insertion of the amputated limb into the body cavity is delayed to allow the formation of the wound epithelium, the limb does regenerate (Goss, 1956b). Regeneration can be similarly prevented if the wound epidermis is not allowed to fully form by repeated excision from the surface of the amputation plane (Thornton, 1957), or if the wound is sutured closed with a skin flap over the amputation site (Mescher, 1976). These experiments demonstrate that epidermal wound healing is necessary for successful limb regeneration.

One of the key signaling pathways for proper wound epidermis formation is Wnt signaling. Multiple studies have established the importance of the Wnt/ $\beta$-catenin pathway in regeneration of the hydra head, zebrafish fin, urodele tail, frog and axolotl limbs (Bode, 2003, Caubit et al., 1997, Kawakami et al., 2006, Poss et al., 2000). Ectopic expression of the Wnt antagonist Dkk1 in axolotls prevents wound epidermis formation and results in regenerative failure. In these animals, the initial migration of epidermal cells seems normal, but the resulting apical epidermal cap lacks its stereotypical shape (Kawakami et al., 2006). The significance of this pathway's role is further demonstrated by its ability to impart some regenerative potential to post-metamorphic frogs, which normally do not regenerate (Kawakami et al., 2006). Intriguingly, Wnts also play a central role in mouse digit tip regeneration. Wnt signaling in the epidermis is required for digit tip regeneration (Takeo et al., 2013). Furthermore, the presumptive responding cells, stem cells in the nail bed, express Lgr6, an R-spondin receptor that modulates Wnt signaling (Lehoczky and Tabin, 2015). Lgr6deficient mice display imperfect digit tip regeneration, underscoring the importance of Wnt signaling in this process.

Cellular proliferation is especially important in the early phases of regeneration, for the wound epidermis to proliferate and give rise to the AEC. A modulator of this response is the TGF- $\beta$-Smad2 signaling pathway. Inhibition of the pathway with an antagonist leads to a decrease in cellular proliferation, and prevents regeneration (Denis et al., 2016, Levesque et al., 2007). During wound healing, the TGF- $\beta$ Smad3 pathway is also active, but inhibition of this pathway does not have an effect on regeneration. Another important pathway for wound healing steps is the epidermal growth factor (EGF) signaling. Blocking EGFR signaling by bathing animals in an EGFR inhibitor for 6 days following amputation results in aberrant wound healing, and aborts regeneration (Farkas et al., 2016). Additionally, EGFR inhibition leads to a significant reduction in epidermal cell proliferation, indicating that the EGFR mediated signaling is essential for functional wound epidermis formation. Msx1 is another protein that is necessary for limb regeneration. Mice can regenerate their digit tips only if the mesenchymal tissue expressing Msx1 is preserved (Han et al., 2003). Interestingly, Bmp4 treatment can rescue Msx1 deficiency, indicating that Bmp4 functions downstream of Msx1. Fibroblast growth factors (Fgfs) also have significant roles in the early events of limb regeneration. Fgf8 is expressed in the basal layers of apical epidermal cap and the mesenchymal tissue that lies directly underneath it. It promotes cellular proliferation in the regenerating blastema (Han et al., 2001, Nacu et al., 2016). A similar role was found for Fgf10, which can impart regenerative capacity to nonregenerative frog limb stumps (Yokoyama et al., 2001).

The immune system plays a vital role to achieve perfect wound healing that will enable a blastema formation. Within a day following amputation, a significant population of macrophages migrate to the amputation site. These numbers continue to rise as wound healing progresses, and declines to baseline as the blastema emerges (Godwin et al., 2013). With the accumulation of macrophages, pro- and anti-inflammatory cytokines also flood the amputation site. This contrasts with mammalian injury models, where pro-inflammatory cytokines are produced first, and anti-inflammatory cytokines come to play much later (Mahdavian Delavary et al., 2011). Identification of such differences between extensive regenerators and mammals will be vital to understand mammalian shortcomings in wound healing. The importance of macrophages in the wound healing response is revealed in an experiment where macrophages are systemically depleted. In the absence of functional macrophages, wound closure still happens, but the limbs do not regenerate (Godwin et al., 2013). Notably, the ability to regenerate can be restored in the following amputations if the macrophage populations were replenished. Macrophages are similarly required for digit tip regeneration in mice, pointing to a conserved principle (Simkin et al., 2017).

Different than salamanders, wound healing in humans ends in the deposition of a scar tissue (Cordeiro and Jacinto, 2013). Scarring is thought to be incompatible with regeneration, and stimulating scar-free healing in mammals might improve regenerative outcomes. Encouragingly, some evidence of scar-free healing is present in mouse digit tip regeneration models (Han et al., 2008, Martin, 1997), and common signaling pathways coordinate this process as well. These parallels hint at the possibility that wound healing responses in mammals might eventually be augmented. Future experimentation in alternative rodent models, such as spiny 
mice, which show scar-free skin healing and enhanced ear-hole punch healing (Gawriluk et al., 2016, Seifert et al., 2012) might uncover enhanced limb regenerative abilities in these animals, if they exist.

\section{Blastema formation and proliferation}

The second stage of limb regeneration is the formation of a translucent, conical shaped structure called the blastema. The blastema lies under the wound epidermis, and is made up of mesenchymal cells that proliferate and eventually give rise to a new limb. The origins of the blastema cells remain widely debated (Bryant et al., 2002), and presently the contribution of stem cells versus cellular dedifferentiation remains unclear for many tissues (Slack, 2006). The homogeneous appearance of blastemal cells initially led to speculation that all of its cells might have equal regenerative potential. However, recent experiments employing
A

salamander

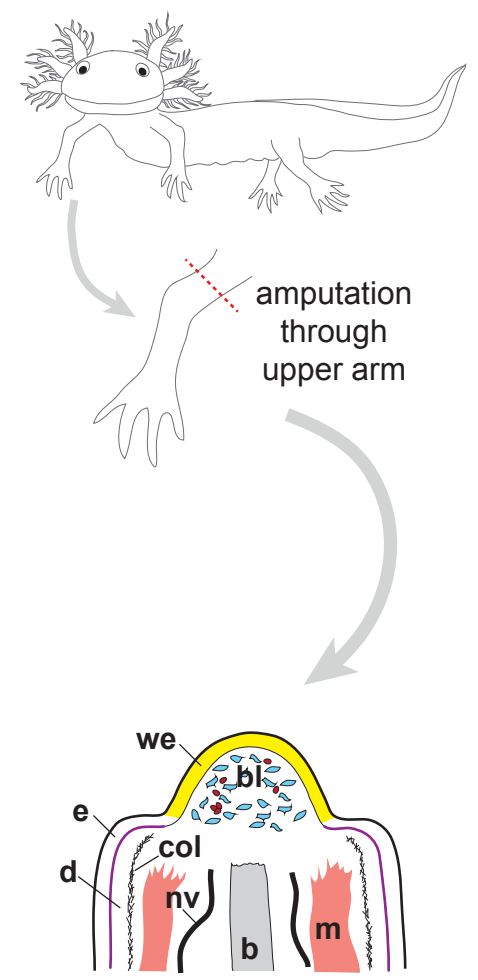

B

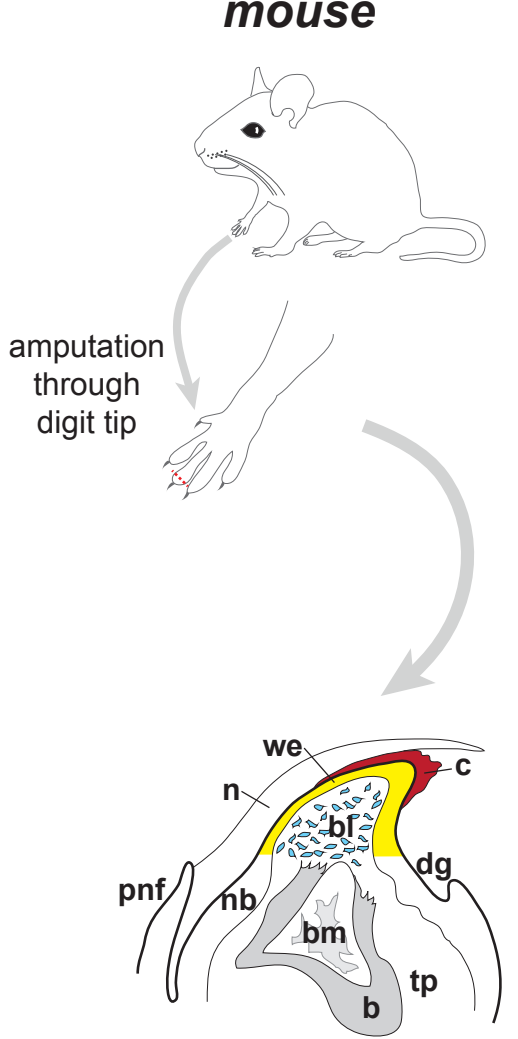

Fig. 2. Comparative anatomy of blastema in salamander and mouse. (A) In axolotl, amputation at the mid-humerus level produces a mid-bud-sized blastema (bl, blue cells) within 7-23 days post-amputation, depending upon animal size. Intermingled with blastema cells are blood cells (shown in red). Overlying the blastema is wound epidermis, also known as apical epidermal cap. Note that more proximal epidermis (e) shows distinctly visible basal lamina (purple), and dermis (d) is bound by a thick collagen mesh (black hatch marks). These features are absent beneath wound epidermis. Nerve: nv; bone: $b$; muscle: $m$; wound epidermis: we; collagen: col. (B) In mouse, amputation through the distal-most phalange at the level of the nail bed, produces a blastema (bl) growth at the distal tip beneath both a clot (c) and a wound epidermis (we), shown around day 10 post-amputation. The nail (n) has already grown past these structures by this time. Histolysing bone (b) is shown with bone marrow $(\mathrm{bm})$. Note that major nerve bundles are not visible in this section plane in mouse digit tips. Nail bed: $n b ;$ toe pad: tp; proximal nail fold: pnf; distal groove: dg. Adapted from (Lehoczky et al., 2011) and (Fernando et al., 2011). transgenic technologies demonstrate that each tissue is likely to e regenerated by progenitor cells with restricted potentials and . Yet, some degree of lasticity within even in this work. More recently, the skeletal elements have been shown to be derived from periskeletal connective tissue cells between salamander blastema cells and mouse digit tip blastema cells (Fig. 2). These comparisons may provide important clues for understanding evolution of appendage regeneration and avenues for design of therapeutic interventions.

Two sources of blastema cells appear to be viable options: dedifferentiation of specialized cell types and recruitment of resident tissue stem cells. These appear to be differentially employed in different animals. In newts, myotubes dedifferentiate to form blastema cells, which then differentiate into muscle cells of the regenerated limb, as evidenced by lineage tracing. In axolotls, the $\mathrm{Pax}^{+}$satellite cells in the muscle tissue are activated upon amputation and are the main contributors to the regenerate muscle (Fei et al., 2017, Morrison et al., 2006, Sandoval-Guzman et al., 2014). In that regard, mammals seem to be similar to axolotls, as the same $\mathrm{Pax} 7^{+}$satellite cell populations are activated following injury (Tedesco et al., 2010). Notably, the permissive zone of limb regeneration - the digit tip-in mice is devoid of musculature. While the consensus view is that regenerative capability is simply imparted by presence of the nail bed stem cells, another (not mutually-exclusive) possibility is that more proximal amputations face some inhibitory influence from muscle. In any case, the molecules that mediate cell-cycle re-entry are still being elucidated. One recently identified for its potential role in progenitor activation is the axolotl MARCKS-Like Protein (AxMLP). Injection of AxMLP protein into uninjured axolotl limbs induces cell cycle re-entry of $\mathrm{Pax} 7^{+}$satellite cells (Sugiura et al., 2016). The axolotl protein can also induce cell cycle re-entry in dedifferentiating myofiber-derived cells and $\mathrm{Pax} 7^{+}$ satellite cells in newts, but requires an injury signal to achieve it. A differential requirement of an injury signal in axolotls and newts might be indicative of a greater number of stem cells cycling in homeostasis in axolotls compared to newts.

Cell cycle re-entry of newt myotubes during the dedifferentiation phase is stimulated by thrombin. Crude thrombin cleaves an unknown factor in bovine sera, which generates an active ligand that acts on in vitro cultured newt multinucleate myotubes (Tanaka et al., 1999). Thrombin is recently shown to cleave 
bone morphogenic proteins, particularly BMP4/7 heterodimers, which induce myotube cell cycle re-entry in regenerating newt limbs (Wagner et al., 2017). Notably, in vitro cultured mouse myotubes also respond to thrombin and regenerating newt serum by reentering the cell cycle, and splitting into either smaller myotubes or mononucleated cells (McGann et al., 2001). Recently, serum from mice with muscle injury was found to stimulate quiescent stem cells are stimulated to a primed " $G_{\text {Alert }}$ " phase upon injection to uninjured mice. This effect was discovered to be mediated by a circulating protease, hepatocyte growth factor activator (HGFA) (Rodgers et al., 2017). HGFA is cleaved by thrombin to become active (Shimomura et al., 1993), and both HGFA and thrombin are induced following injury (Coughlin, 2000), suggesting that HGFA might potentially be the factor that enable myotube cell cycle reentry. Further work will be necessary to investigate this possibility.

A major component of successful blastema formation is the existing nerve. Denervation results in failure to generate a mature blastema, resulting in only a stump with fibrotic scar tissue and a few blastema cells with defective cell cycling kinetics (Barger and Tassava, 1985, Brockes, 1987, Liversage and McLaughlin, 1983, Maden, 1978, Maden, 1979). Importantly, nerves are also sufficient to induce a blastema in a permissive environment. Nerve bundles redirected to a skin injury are capable of directing a blastema formation. A modulator of this process is the newt Anterior Gradient protein (nAG). nAG is expressed both in regenerating nerves and the wound epidermis, and misexpression nAG after denervation can rescue the regeneration phenotype (Kumar et al., 2007). Another known mediator of this process is Neureglin-1 (NRG1), which is expressed in regenerating nerves, wound epidermis, and the blastema. nAG is also sufficient to allow blastema formation, as demonstrated by the placing of NRG1 soaked beads into amputated and nerve deficient axolotl limbs (Farkas et al., 2016). Importantly, nerves also have a role in mammalian digit tip regeneration, as evidenced by deficits in regeneration following denervation (Mohammad and Neufeld, 2000, Rinkevich et al., 2014, Takeo et al., 2013). This phenotype can be rescued by transplantation of Schwann cell precursors, which secrete pro-regenerative factors such as oncostatin M (OSM) and platelet-derived growth factor AA (PDGF-AA) (Johnston et al., 2016). These findings demonstrate why the digit has to be innervated for mammalian digit tip regeneration.

Sustenance of the blastema is as important as forming it. The blastema has to reach a critical size before it flattens and starts patterning to give rise to the new limb. Known molecular regulators of continuous blastema proliferation are the Piwi-like proteins 1 and 2 (PL1 and PL2). PL1 and PL2 are expressed in the blastema, and their depletion halts blastema growth, and increases cell death (Zhu et al., 2012). This is in line with PL1 and PL2's involvement in germline development (Saxe and Lin, 2011), and demonstrates how organisms adopt similar mechanisms for self-renewal in both developmental and regenerative systems. More recently, a role of axolotl orthologs of cold-inducible RNA binding protein (Cirbp) and Kazal-type serine peptidase inhibitor domain 1 (Kazald1) in blastema proliferation were also described (Bryant et al., 2017a). Depletion of Kazald1 hinders blastema growth, and results delays chondrification and digit differentiation. Cirbp knockdown leads to increased apoptosis in the blastema, suggesting it might have cytoprotective roles.

\section{Patterning the limb: the re-development phase}

Once the blastema reaches a critical size, it flattens and begins to differentiate into the tissues that will form a new limb. This stage has striking resemblances to limb development with respect to the molecular pathways that are important in establishing limb axes and patterning (Roy et al., 2000). The two main differences are the size of the limb, which must match the animal's current size, and existing structures in to which the new tissue must be integrated. Therefore, it is plausible that there would be additional pathways to coordinate these intricacies.

The blastema contains critical information about its positional identity. Transplantation of the blastema into regeneration permissive locations results in generation of structures that reflect the blastema's retained identity. For example, when limb blastemas are grafted to the dorsal fin, they generate limb tissues (Polezhaev, 1934). This suggests there is the blastema is autonomous, at least to some degree once it reaches a certain size (Stocum, 1984).

The anterior-posterior (AP) axis of the regenerate limb is controlled much like in limb development. In both processes, sonic hedgehog (Shh) signaling has a conserved role in establishing the AP axis. It is expressed on the posterior side of blastemas and limb buds, and ectopic expression of Shh on the anterior side in either context causes ectopic digit formation (Riddle et al., 1993, Roy et al., 2000). Inhibition of Shh signaling during axolotl limb regeneration with a chemical inhibitor leads to the absence of posterior digits (Roy and Gardiner, 2002).

Establishing the proximodistal axis of the limb is just as crucial as the anterior-posterior axis. The regeneration process should only produce body parts that are lost; the amputation of a hand should only give rise to a new hand, whereas amputation of the arm should regenerate the entire arm. Two known regulators of this axis are retinoic acid and Prod1. During limb regeneration, retinoic acid signaling is observed in the apical epidermal cap (Scadding and Maden, 1994). Retinoic acid administration to regenerating limbs results duplication of proximal elements in a concentration dependent manner (Maden, 1983). Furthermore, a blastema arising from a distal amputation can be instructed to give rise to proximal limb structures upon treatment with retinoic acid (Crawford and Stocum, 1988, Maden, 1982, Monaghan and Maden, 2012, Niazi and Saxena, 1978). The role of Prod1 in the proximodistal axis was initially suggested by the finding that retinoic acid treatment upregulates Prod1 expression in the blastema and the limb, and to a greater extent in the proximal limb (da Silva et al., 2002). A later study found that overexpression of Prod1 can push distal blastema cells to translocate to a proximal location and assume a more proximal identity (Echeverri and Tanaka, 2005). Meis proteins, homeobox-containing factors whose activities are downstream of retinoic acid, are also important for imparting proximodistal information in blastema cells (Mercader et al., 2005). Similar to Prod1, overexpression of Meis proteins in blastemas led to proximal localization of expressing cells in the regenerate limb (Mercader et al., 2005).

The dorsal-ventral (DV) axis occurs parallel to other axes, and is mediated by Wnt7a. During limb development, Wnt7a is expressed from the dorsal ectoderm, and induces the expression of Lmx1 in the dorsal mesoderm (Cygan et al., 1997, Dealy et al., 1993, Parr and McMahon, 1995, Riddle et al., 1995, Vogel et al., 
1995). In the ventral ectoderm, En1 represses Wnt7a to allow for a ventral identity. Loss of either Wnt7a or Lmx1 alters dorsal structures to ventral fate, suggesting ventral fate is the default state (Chen et al., 1998, Cygan et al., 1997, Parr and McMahon, 1995, Rodriguez-Esteban et al., 1998). During limb regeneration, $\mathrm{Lm} \times 1$ is expressed in the dorsal mesenchyme of Xenopus tadpole blastemas, in a similar pattern to that in the limb bud, suggesting it is also the mediator of DV patterning during limb regeneration (Matsuda et al., 2001). However, whether its function is conserved in regeneration remains to be tested.

In sumary, axolotls and other master regenerators successfully re-establish all three major axes as part of their regenerative program, and their innate ability to replace precisely what was lost will be critical to understand if future regenerative therapies, yet to be developed, are to have maximum value to patients.

\section{Sizing the limb: the new part must match the old}

Upon completion of limb patterning, the limb must now grow to match the size of the contralateral limb. This is also an important concept in development, yet it is relatively understudied. A mutagenesis screen in zebrafish has implicated a potassium channel, Kcnk5b, in regulating appendage size. Locally increased activity of this channel increases fin and barbel size (Perathoner et al., 2014). Although the exact pathway through which this is achieved remains unknown, bioelectrical signaling clearly has a role in appendage size control. This type of local control of appendage size during development has also been demonstrated in salamanders. When the limb buds of two different salamander species of different sizes were swapped, the limbs that were produced matched the size of their hosts (Twitty and Schwind, 1931). This experiment indicates that information on the size of the limb is encoded in the limb bud.

Nerves are important in this growth phase of limbs. Denervation of peripheral limbs during limb development frogs leads to a diminished rate of bone maturation, and smaller limbs (Dietz, 1987). Nerves are also implicated in limb size in the context of regeneration. Denervation of the newt limb after the blastema formation results in limbs that are smaller than they should be, as compared to innervated controls (Singer and Craven, 1948). This points the importance of nerves in determining the final size of the limb. A recent paper also found that repeated removal of axolotl limb buds can give rise to miniaturized, nerve-deficient limb (Bryant et al., 2017b). Interestingly, this effect is permanent, and cannot be reversed even after subsequent amputations. Further experimentation will be required to determine if repeated bud removal leads to miniaturized limbs because of limited numbers of progenitor cells and/or a deficiency in the limb growth phase following patterning. Either of these possible mechanisms could be connected to inadequate connections between the limb bud and the growing body. Dysregulation in the opposite direction-too much growth-could be equally problematic. A possible example of this phenomenon might be considered in the distinctive overshoot in bone formation in regenerating mouse digit tips (Fernando et al., 2011, Sammarco et al., 2014).

\section{Limitations to limb regeneration}

While experimental manipulations can limit an animal's ability to regenerate, there are also some naturally occurring limitations to an animal's regenerative response. These include species, age, and the extent of injury. For example, mice can only regenerate the distal part of their digits that include the terminal phalangeal bone (Han et al., 2008). Humans can do the same, but it appears to be restricted to children (Douglas, 1972, Illingworth, 1974). Similarly, frogs can fully regenerate their limbs only as tadpoles (Dent, 1962). Regenerative abilities can differ even within the same animal; some lizards can regenerate their tails, but not their limbs.

A more basic question is whether regeneration can occur in an animal that is challenged with repeated insults to the same organ. The answer depends on many factors, including the species, age and the injured body part. For example, newts are capable of regenerating their lenses up to 18 times upon repeated removal (Eguchi et al., 2011). This experiment not only demonstrates lens regeneration in newts occurs in both repeatedly challenged animals and in older animals. However, their limb regeneration capacities are reportedly significantly diminished after five amputations (Dearlove and Dresden, 1976), even though they still clear senescent cells (Yun et al., 2015). In contrast, successful repeated regeneration is severely compromised in axolotls (Bryant et al., 2017c). Initially, regenerated limbs retain similar frequencies of cells from different lineages for up to two amputations (Flowers et al., 2017). However, axolotls undergoing more rounds of amputation at the same plane aberrantly upregulate many transcripts whose misregulation might antagonize regeneration (Bryant et al., 2017c). One example is amphiregulin, which when misexpressed early, is sufficient to impair regeneration. The extent of successful repeated regeneration of mouse digit tips has not yet been fully explored.

\section{Non-amputation model to study limb regeneration}

Limb regeneration is traditionally studied in amputation models, but another important model relies on the induction of an ectopic limb at a regeneration permissive site. Normally, a superficial skin wound created on the axolotl arm heals scar free. If a nerve is deviated to this wound, a transient bump resembling an ectopic blastema forms (Endo et al., 2004, Satoh et al., 2007). If a piece of skin from the contralateral limb is grafted on beside the wound, together with redirection of the nerve, the emerging bump gives rise to an ectopic limb. This model, termed the accessory limb model (ALM) (reviewed in (Seyedhassantehrani et al., 2017)), elegantly demonstrates the requirement of signals from the wound itself, the nerves, and positional information from contralateral cells that are opposite side of the wound. It is particularly useful for studying the early events of regeneration. Experiments of the accessory limb model complements nicely to the traditional loss-of-function experiments, and help reveal which signals are pro-regenerative.

\section{Understanding the connection between regeneration and cancer}

One feature of salamanders that has fascinated scientists for decades is their apparent resistance to tumor formation. It is very appealing to consider a possible link of this property to their vast capacity to regenerate. Early experiments that exposed newts to known human carcinogens demonstrated that newts rarely form solid tumors (Breedis, 1952). This was a very interesting finding by itself, but what made it particularly exciting for the regeneration field was that the carcinogen treatment induced the formation of 
an accessory limb. These experiments showed that what caused humans to form tumors initiated a regenerative response in newts.

The molecular cues to the underpinnings of this regenerative response come from experiments that study mechanisms of dedifferentiation in salamanders and mammals. One hypothesis to explain why salamanders are potent regenerators while mammals are not is that mammals harbor an enhanced repertoire of tumor suppressors, which might be hindering dedifferentiation, and as a result, regeneration (Pomerantz and Blau, 2013). This is exemplified by the roles of tumor suppressors p53 and Arf in cell cycle reentry. During limb regeneration, some post-mitotic cells may need to lose their differentiated identity, reenter the cell cycle, and proliferate. In axolotls, downregulation of the tumor suppressor p53 is required for differentiated cells to reenter the cell cycle, allowing the formation of progenitor cells that contribute to the blastema (Yun et al., 2013). The axolotl p53 is slightly different than its human counterpart, and substituting specific axolotl amino acid sequences in the human p53 renders it defective in some assays (Villiard et al., 2007). The downregulation of p53 is mediated by Arf, a tumor suppressor that stabilizes p53 through binding Mdm2. Importantly, no ancestral Arf has been found in lower vertebrates, with the earliest ortholog found in chickens (Gilley and Fried, 2001, Kim et al., 2003). This explains why newt myotubes cells reenter the cell cycle following inactivation of only $\mathrm{Rb}$ by phosphorylation (Tanaka et al., 1997), whereas Rb loss is insufficient to induce cell cycle reentry in differentiated mouse cells (Camarda et al., 2004, Huh et al., 2004). Mouse cells can be induced to reenter the cell cycle by the combined transient inactivation of $\mathrm{Rb}$ and Arf (Pajcini et al., 2010). These experiments suggest that what gives mammalian cells an advantage in resisting the spread of DNA damage could also be factors that handicap them in mounting a regenerative response. Consequently, we must face the possibility that differentiated axolotl cells do not face the same barriers differentiated human cells encounter to successfully regenerate, and a full understanding of regenerative roadblocks is needed.

\section{Evolutionary considerations}

Evolutionary capabilities vary widely across the animal kingdom, and it is unclear why only some animals are capable of regenerating entire limbs. The intuitive view is that limb regeneration is an ancestral ability that was progressively lost in the evolution of vertebrates (Bely and Nyberg, 2010). Fish can usually regenerate their fins, and it has been proposed that vertebrates had the ability to regenerate appendages during fin to limb transition (Cuervo et al., 2012). Also, a recent fossil study found that a primitive temnospondyl amphibian, Micromelerpeton, was capable of regenerating limbs, based on abnormalities that are associated with limb regeneration (Frobisch et al., 2014). This indicates that the ability to regenerate limbs is not restricted to modern salamanders, but is possibly an attribute of non-amniote tetrapods.

Salamanders are the only modern tetrapod vertebrates that can regenerate their limbs as adults. One might wonder why only salamanders reserved this capability whereas other extant tetrapods did not. One consideration is that the ability to regenerate limbs is energetically expensive. It is a massive undertaking that uses a lot of the animal's resources, and presumably sustained only if it gives the animal a selective advantage. From this perspective, it is crucial for salamanders to retain regenerative capabilities. As larvae, salamanders show cannibalistic behaviors, and limb regeneration is essential for their survival for them to swim out of the water after they metamorphose. This property directly affects their survival into adulthood and sexual maturity. With this line of reasoning, one would expect other species to also be under similar selective pressure. However, for regenerative abilities to be selected, loss if a limb should not be a rare event. It should be encountered often enough to be a consistent problem for the organism (Brockes and Kumar, 2008, Goss, 1969, Reichman, 1984).

Frogs are other amphibians that have the capacity to fully regenerate their limbs, but they can do so only as tadpoles. Many molecular pathways involved in this regeneration process are common in tadpoles and salamanders, such as FGF signaling (D'Jamoos et al., 1998, Mullen et al., 1996, Tsonis, 2000, Zenjari et al., 1997). The regenerative ability of frogs progressively declines with development. Post-metamorphic frogs can regenerate a cartilaginous spike at best (Dent, 1962, Sessions and Bryant, 1988). A member of the Anterior gradient gene family, Ag1, has been implicated in this difference. Importantly, no $A g 1$ orthologs were found amniotes, but are found in fishes, frogs, and salamanders, which are all highly regenerative species (Ivanova et al., 2013). This finding is in favor of the idea that regenerative abilities were gradually lost throughout evolution.

It is tempting to think that humans already possess the tools necessary to regenerate entire limbs. However, another possibility is that the ability to regenerate limbs evolved locally in salamanders. According to this view, limb regeneration relies on processes that are conserved, such as development and wound healing, that are present in both regenerative and non-regenerative organisms. However, the elements that coordinate these processes to produce a regenerative response only emerged in taxa that are capable of limb regeneration, i.e., salamanders. One evidence for this view comes from the discovery Prod1, a protein that is specific to salamanders, that is involved in growth and patterning of the regenerating limb (Garza-Garcia et al., 2010). The lack of any known orthologs of Prod1 suggests that although some ancestral machinery may be present in all organisms, it might take additional, locally evolved components to orchestrate full limb regeneration.

\section{Perspectives for the future}

Looking at regenerative capacities across the animal kingdom, we are now at the era of uncovering many of the molecular pathways that must be carefully coordinated for regenerative success. The increased toolkit for molecular investigation, especially in the salamanders, is providing a wealth of new candidate factors to consider (reviewed in Haas and Whited, 2017). The recent full-genome sequence of the axolotl is an invaluable resource for future genetic studies (Nowoshilow et al., 2018). Clues from salamanders and mammalian regeneration models will allow comparisons regarding which molecular features are necessary to give rise to a new limb. Axolotls are excellent models for extensive regeneration, and mouse models show restricted spontaneous repair of complex limb injuries. Humans and mice have declining regenerative capabilities as they age, hinting at the possibility that these latent abilities might eventually be resurfaced with the right manipulation. One area to focus now is how our knowledge of regeneration in axolotls and mice could be integrated. Pathways revealed in axolotls will hopefully be translated into approaches for evoking possibly latent 
potentials in mammals. Even though the ultimate goal of human limb regeneration may be still be in the distance, the principles discovered could meanwhile aid in enhancing wound healing and regenerative responses in more limited circumstances requiring complex tissue regeneration.

\section{Acknowledgements}

We thank Jessica Lehoczky for helpful comments and the Harvard Medical School Division of Biological and Biomedical Sciences, the NIH Director's Office, the Paul G. Allen Family Foundation, and Brigham \& Women's Hospital for support.

\section{References}

BARGER, P.M. and TASSAVA, R.A. (1985). Kinetics of cell cycle entry in innervated and denervated forelimb stumps of larval Ambystoma. J. Exp. Zool. Part A: Ecol. Genet. Physiol 233: 151-154.

BELY,A.E. and NYBERG, K.G. (2010). Evolution of animal regeneration: re-emergence of a field. Trends Ecol Evol 25: 161-70.

BODE, H.R. (2003). Head regeneration in Hydra. Dev Dyn 226: 225-236.

BORGENS, R.B. (1982). Mice regrow the tips of their foretoes. Science 217: 747-750.

BREEDIS, C. (1952). Induction of accessory limbs and of sarcoma in the Newt (Triturus viridescens) with carcinogenic substances. Cancer Res 12: 861-86.

BROCKES, J.P. (1987). The nerve dependence of amphibian limb regeneration. $J$ Exp Biol 132: 79-91.

BROCKES, J.P. and KUMAR, A. (2005). Appendage regeneration in adult vertebrates and implications for regenerative medicine. Science 310: 1919-1923.

BROCKES, J.P. and KUMAR, A. (2008). Comparative aspects of animal regeneration. Annu Rev Cell Dev Biol 24: 525-549.

BRYANT, D.M., JOHNSON, K., DITOMMASO, T., TICKLE, T., COUGER, M.B., PAYZIN-DOGRU, D., LEE, T.J., LEIGH, N.D., KUO, T.H., DAVIS, F.G. et al., (2017a). A Tissue-Mapped Axolotl De Novo Transcriptome Enables Identification of Limb Regeneration Factors. Cell Rep 18: 762-776.

BRYANT, D.M., SOUSOUNIS, K., FARKAS, J.E., BRYANT, S., THAO, N., GUZIKOWSKI, A.R., MONAGHAN, J.R., LEVIN, M. and WHITED, J.L. (2017b). Repeated removal of developing limb buds permanently reduces appendage size in the highly-regenerative axolotl. Dev Biol 424: 1-9.

BRYANT, D.M., SOUSOUNIS, K., PAYZIN-DOGRU, D., BRYANT, S., SANDOVAL, A.G.W., MARTINEZ FERNANDEZ, J., MARIANO, R., OSHIRO, R., WONG, A.Y., LEIGH, N.D. et al., (2017c). Identification of regenerative roadblocks via repeat deployment of limb regeneration in axolotls. NPJ Regen Med 2: 30.

BRYANT, S.V., ENDO, T. and GARDINER, D.M. (2002). Vertebrate limb regeneration and the origin of limb stem cells. Int J Dev Biol 46: 887-896.

CAMARDA, G., SIEPI, F., PAJALUNGA, D., BERNARDINI, C., ROSSI, R., MONTECUCCO, A., MECCIA, E. and CRESCENZI, M. (2004). A pRb-independent mechanism preserves the postmitotic state in terminally differentiated skeletal muscle cells. J Cell Biol 167: 417-423.

CAUBIT, X., NICOLAS, S. and LE PARCO, Y. (1997). Possible roles for Wnt genes in growth and axial patterning during regeneration of the tail in urodele amphibians. Dev Dyn 210: 1-10.

CHEN, H., LUN, Y., OVCHINNIKOV, D., KOKUBO, H., OBERG, K.C., PEPICELLI, C.V., GAN, L., LEE, B. and JOHNSON, R.L. (1998). Limb and kidney defects in $L m \times 1 b$ mutant mice suggest an involvement of LMX1B in human nail patella syndrome. Nat Genet 19: 51-55.

CORDEIRO, J.V. and JACINTO, A. (2013). The role of transcription-independent damage signals in the initiation of epithelial wound healing. Nat Rev Mol Cell Biol 14: 249-262.

COUGHLIN, S.R. (2000). Thrombin signalling and protease-activated receptors. Nature 407: 258.

CRAWFORD, K. and STOCUM, D.L. (1988). Retinoic acid coordinately proximalizes regenerate pattern and blastema differential affinity in axolotl limbs. Development 102: 687-698

CUERVO, R., HERNANDEZ-MARTINEZ, R., CHIMAL-MONROY, J., MERCHANTLARIOS, H. and COVARRUBIAS, L. (2012). Full regeneration of the tribasal
Polypterus fin. Proc Natl Acad Sci USA 109: 3838-3843.

CURRIE, J.D., KAWAGUCHI, A., TRASPAS, R.M., SCHUEZ, M., CHARA, O. and TANAKA, E.M. (2016). Live Imaging of Axolotl Digit Regeneration Reveals Spatiotemporal Choreography of Diverse Connective Tissue Progenitor Pools. Dev Cell 39: 411-423.

CYGAN, J.A., JOHNSON, R.L. and MCMAHON, A.P. (1997). Novel regulatory interactions revealed by studies of murine limb pattern in Wnt-7a and En-1 mutants. Development 124: 5021-5032.

D'JAMOOS, C.A., MCMAHON, G. and TSONIS, P.A. (1998). Fibroblast growth factor receptors regulate the ability for hindlimb regeneration in Xenopus laevis. Wound Repair Regen 6: 388-397.

DA SILVA, S.M., GATES, P.B. and BROCKES, J.P. (2002). The newt ortholog of CD59 is implicated in proximodistal identity during amphibian limb regeneration. Dev Cell 3: 547-555

DALYELL, J.G.S. (1814). Observations on some interesting phenomena in animal physiology, exhibited by several species of Planariae: illustrated by coloured figures of living animals / by John Graham Dalyell. Archibald Constable, Edinburgh.

DEALY, C.N., ROTH, A., FERRARI, D., BROWN, A.M. and KOSHER, R.A. (1993). Wnt-5a and Wnt-7a are expressed in the developing chick limb bud in a manner suggesting roles in pattern formation along the proximodistal and dorsoventral axes. Mech Dev 43: 175-186.

DEARLOVE, G.E. and DRESDEN, M.H. (1976). Regenerative abnormalities in Notophthalmus viridescens induced by repeated amputations. J Exp Zool 196: 251-262.

DENIS, J.F., SADER, F., GATIEN, S., VILLIARD, E., PHILIP, A. and ROY, S. (2016) Activation of Smad2 but not Smad3 is required to mediate TGF-beta signaling during axolotl limb regeneration. Development 143: 3481-3490.

DENT, J.N. (1962). Limb regeneration in larvae and metamorphosing individuals of the South African clawed toad. J Morphol 110: 61-77.

DIETZ, F.R. (1987). Effect of peripheral nerve on limb development. $J$ Orthop Res 5: $576-585$.

DOUGLAS, B.S. (1972). Conservative management of guillotine amputation of the finger in children. Aust Paediatr J 8: 86-89.

ECHEVERRI, K. and TANAKA, E.M. (2005). Proximodistal patterning during limb regeneration. Dev Biol 279: 391-401.

EGUCHI, G., EGUCHI, Y., NAKAMURA, K., YADAV, M.C., MILLAN, J.L. and TSONIS, P.A. (2011). Regenerative capacity in newts is not altered by repeated regeneration and ageing. Nat Commun 2: 384.

ENDO, T., BRYANT, S.V. and GARDINER, D.M. (2004). A stepwise model system for limb regeneration. Dev Biol 270: 135-145.

FARKAS, J.E., FREITAS, P.D., BRYANT, D.M., WHITED, J.L. and MONAGHAN, J.R. (2016). Neuregulin-1 signaling is essential for nerve-dependent axolotl limb regeneration. Development 143: 2724-2731.

FEI, J.F., SCHUEZ, M., KNAPP, D., TANIGUCHI, Y., DRECHSEL, D.N. and TANAKA, E.M. (2017). Efficient gene knockin in axolotl and its use to test the role of satellite cells in limb regeneration. Proc Natl Acad Sci USA 114: 12501-12506.

FERNANDO, W.A., LEININGER, E., SIMKIN, J., LI, N., MALCOM, C.A., SATHYAMOORTHI, S., HAN, M. and MUNEOKA, K. (2011). Wound healing and blastema formation in regenerating digit tips of adult mice. Dev Biol 350: 301-310.

FLOWERS, G.P., SANOR, L.D. and CREWS, C.M. (2017). Lineage tracing of genomeedited alleles reveals high fidelity axolotl limb regeneration. eLife 6 .

FROBISCH, N.B., BICKELMANN, C. and WITZMANN, F. (2014). Early evolution of limb regeneration in tetrapods: evidence from a 300-million-year-old amphibian. Proc Biol Sci 281: 20141550.

GARZA-GARCIA, A.A., DRISCOLL, P.C. and BROCKES, J.P. (2010). Evidence for the local evolution of mechanisms underlying limb regeneration in salamanders. Integr Comp Biol 50: 528-535.

GAWRILUK, T.R., SIMKIN, J., THOMPSON, K.L., BISWAS, S.K., CLARE-SALZLER, Z., KIMANI, J.M., KIAMA, S.G., SMITH, J.J., EZENWA, V.O. and SEIFERT, A.W. (2016). Comparative analysis of ear-hole closure identifies epimorphic regeneration as a discrete trait in mammals. Nat Commun 7: 11164.

GILLEY, J. and FRIED, M. (2001). One INK4 gene and no ARF at the Fugu equivalent of the human INK4A/ARF/INK4B tumour suppressor locus. Oncogene20:7447-7452.

GODWIN, J.W., PINTO, A.R. and ROSENTHAL, N.A. (2013). Macrophages are required for adult salamander limb regeneration. Proc. Natl. Acad. Sci. USA 110: $9415-9420$ 
GOSS, R.J. (1956a). Regenerative inhibition following limb amputation and immediate insertion into the body cavity. Anat. Rec. 126: 15-27.

GOSS, R.J. (1956b). The regenerative responses of amputated limbs to delayed insertion into the body cavity. Anat. Rec. 126: 283-297.

GOSS, R.J. (1969). Principles of regeneration. Academic Press.

HAN, M., YANG, X., FARRINGTON, J.E. and MUNEOKA, K. (2003). Digit regeneration is regulated by Msx1 and BMP4 in fetal mice. Development 130: 5123-5132.

HAN, M., YANG, X., LEE, J., ALLAN, C.H. and MUNEOKA, K. (2008). Development and regeneration of the neonatal digit tip in mice. Dev Biol 315: 125-135.

HAN, M.J., AN, J.Y. and KIM, W.S. (2001). Expression patterns of Fgf-8 during development and limb regeneration of the axolotl. Dev Dyn 220: 40-48.

HUH, M.S., PARKER, M.H., SCIME, A., PARKS, R. and RUDNICKI, M.A. (2004). Rb is required for progression through myogenic differentiation but not maintenance of terminal differentiation. J Cell Biol 166: 865-876.

ILLINGWORTH, C.M. (1974). Trapped fingers and amputated finger tips in children. $J$ Pediatr Surg 9: 853-858.

IVANOVA, A.S., TERESHINA, M.B., ERMAKOVA, G.V., BELOUSOV, V.V. and ZARAISKY, A.G. (2013). Agr genes, missing in amniotes, are involved in the body appendages regeneration in frog tadpoles. Sci Rep 3: 1279.

JOHNSON, K., BATEMAN, J., DITOMMASO, T., WONG, A.Y. and WHITED, J.L. (2018). Systemic cell cycle activation is induced following complex tissue injury in axolotl. Dev Biol 433: 461-472.

JOHNSTON, A.P., YUZWA, S.A., CARR, M.J., MAHMUD, N., STORER, M.A., KRAUSE, M.P., JONES, K., PAUL, S., KAPLAN, D.R. and MILLER, F.D. (2016). Dedifferentiated Schwann Cell Precursors Secreting Paracrine Factors Are Required for Regeneration of the Mammalian Digit Tip. Cell Stem Cell 19: 433-448.

KAWAKAMI, Y., RODRIGUEZ ESTEBAN, C., RAYA, M., KAWAKAMI, H., MARTI, M., DUBOVA, I. and IZPISUA BELMONTE, J.C. (2006). Wnt/beta-catenin signaling regulates vertebrate limb regeneration. Genes Dev 20: 3232-3237.

KIM, S.H., MITCHELL, M., FUJII, H., LLANOS, S. and PETERS, G. (2003). Absence of p16INK4a and truncation of ARF tumor suppressors in chickens. Proc Natl Acad Sci USA 100: 211-216.

KRAGL, M., KNAPP, D., NACU, E., KHATTAK, S., MADEN, M., EPPERLEIN, H.H. and TANAKA, E.M. (2009). Cells keep a memory of their tissue origin during axolotl limb regeneration. Nature 460: 60-65.

KUMAR, A., GODWIN, J.W., GATES, P.B., GARZA-GARCIA, A.A. and BROCKES, J.P. (2007). Molecular basis for the nerve dependence of limb regeneration in an adult vertebrate. Science 318: 772-777.

LEHOCZKY, J.A., ROBERT, B. and TABIN, C.J. (2011). Mouse digit tip regeneration is mediated by fate-restricted progenitor cells. Proc Natl Acad Sci USA 108: 20609-20614.

LEHOCZKY, J.A. and TABIN, C.J. (2015). Lgr6 marks nail stem cells and is required for digit tip regeneration. Proc Natl Acad Sci USA 112: 13249-13254

LEVESQUE, M., GATIEN, S., FINNSON, K., DESMEULES, S., VILLIARD, E., PILOTE, M., PHILIP, A. and ROY, S. (2007). Transforming growth factor: beta signaling is essential for limb regeneration in axolotls. PLoS One 2: e1227.

LIVERSAGE, R.A. and MCLAUGHLIN, D.S. (1983). Effects of delayed amputation on denervated forelimbs of adult newt. J Embryol Exp Morphol 75: 1-10.

MADEN, M. (1978). Neurotrophic control of the cell cycle during amphibian limb regeneration. J Embryol Exp Morphol 48: 169-175.

MADEN, M. (1979). Neurotrophic and x-ray blocks in the blastemal cell cycle. $J$ Embryol Exp Morphol 50: 169-173.

MADEN, M. (1982). Vitamin A and pattern formation in the regenerating limb. Nature 295: $672-675$

MADEN, M. (1983). The effect of vitamin A on the regenerating axolotl limb. J Embryol Exp Morphol 77: 273-295

MAHDAVIAN DELAVARY, B., VAN DER VEER, W.M., VAN EGMOND, M., NIESSEN, F.B. and BEELEN, R.H. (2011). Macrophages in skin injury and repair. Immunobiol. 216: 753-762.

MARTIN, P. (1997). Wound healing--aiming for perfect skin regeneration. Science 276: 75-81

MATSUDA, H., YOKOYAMA, H., ENDO, T., TAMURA, K. and IDE, H. (2001). An epidermal signal regulates $\mathrm{Lmx}-1$ expression and dorsal-ventral pattern during Xenopus limb regeneration. Dev Biol 229: 351-362.
MCCUSKER, C.D., DIAZ-CASTILLO, C., SOSNIK, J., A, Q.P. and GARDINER, D.M (2016). Cartilage and bone cells do not participate in skeletal regeneration in Ambystoma mexicanum limbs. Dev Biol 416: 26-33.

MCGANN, C.J., ODELBERG, S.J. and KEATING, M.T. (2001). Mammalian myotube dedifferentiation induced by newt regeneration extract. Proc Natl Acad Sci USA 98: 13699-13704.

MERCADER, N., TANAKA, E.M. and TORRES, M. (2005). Proximodistal identity during vertebrate limb regeneration is regulated by Meis homeodomain proteins. Development 132: 4131-4142.

MESCHER, A.L. (1976). Effects on adult newt limb regeneration of partial and complete skin flaps over the amputation surface. J Exp Zool 195: 117-128.

MOHAMMAD, K.S. and NEUFELD, D.A. (2000). Denervation retards but does not prevent toetip regeneration. Wound Repair Regen 8: 277-281.

MONAGHAN, J.R. and MADEN, M. (2012). Visualization of retinoic acid signaling in transgenic axolotls during limb development and regeneration. Dev Bio/368: 63-75.

MORGAN, T.H. (1901). Regeneration. The Macmillan Company.

MORRISON, J.I., LÖÖF, S., HE, P. and SIMON, A. (2006). Salamander limb regeneration involves the activation of a multipotent skeletal muscle satellite cell population. J Cell Biol 172: 433-440.

MULLEN, L.M., BRYANT, S.V., TOROK, M.A., BLUMBERG, B. and GARDINER, D.M. (1996). Nerve dependency of regeneration: the role of Distal-less and FGF signaling in amphibian limb regeneration. Development 122: 3487-3497.

MUNEOKA, K., ALLAN, C.H., YANG, X., LEE, J. and HAN, M. (2008). Mammalian regeneration and regenerative medicine. Birth Defects Res C Embryo Today 84: 265-280

MUNEOKA, K., HOLLER-DINSMORE, G. and BRYANT, S.V. (1986). Intrinsic control of regenerative loss in Xenopus laevis limbs. $J$ Exp Zool 240: 47-54.

NACU, E., GROMBERG, E., OLIVEIRA, C.R., DRECHSEL, D. and TANAKA, E.M. (2016). FGF8 and SHH substitute for anterior-posterior tissue interactions to induce limb regeneration. Nature 533: 407-410.

NEUFELD, D.A. and ZHAO, W. (1995). Bone regrowth after digit tip amputation in mice is equivalent in adults and neonates. Wound Repair Regen 3: 461-466.

NIAZI, I.A. and SAXENA, S. (1978). Abnormal hind limb regeneration in tadpoles of the toad, Bufo andersoni, exposed to excess vitamin A. Folia Biol (Krakow)26:3-8.

NOWOSHILOW, S., SCHLOISSNIG, S., FEI, J.-F., DAHL, A., PANG, A.W.C., PIPPEL, M., WINKLER, S., HASTIE, A.R., YOUNG, G., ROSCITO, J.G., FALCON, F., KNAPP, D., POWELL, S., CRUZ, A., CAO, H., HABERMANN, B., HILLER, M., TANAKA, E.M., and MYERS, E.W. (2018). The axolotl genome and the evolution of key tissue formation regulators. Nature 554: 50-55.

ODELBERG, S.J. (2005). Cellular plasticity in vertebrate regeneration. Anat $\operatorname{Rec} B$ New Anat 287: 25-35.

PAJCINI, K.V., CORBEL, S.Y., SAGE, J., POMERANTZ, J.H. and BLAU, H.M. (2010). Transient inactivation of $\mathrm{Rb}$ and $\mathrm{ARF}$ yields regenerative cells from postmitotic mammalian muscle. Cell Stem Cell 7: 198-213.

PALLAS, P.S. and PAULI, J. (1780). Spicilegia Zoologica: Quibus Novae Imprimis Et Obscurae Animalium Species Iconibus, Descriptionibus Atque Commentariis Illustrantur. Prostant Apud Joachimum Pauli.

PARR, B.A. and MCMAHON, A.P. (1995). Dorsalizing signal Wnt-7a required for normal polarity of D-V and A-P axes of mouse limb. Nature 374: 350-353.

PERATHONER, S., DAANE, J.M., HENRION, U., SEEBOHM, G., HIGDON, C.W., JOHNSON, S.L., NUSSLEIN-VOLHARD, C. and HARRIS, M.P. (2014). Bioelectric signaling regulates size in zebrafish fins. PLoS Genet 10: e1004080.

POLEZHAEV, L. (1934). Über die Determination des Regenerats. In CR Dokl Acad SCi URSS 4: 468-472.

POMERANTZ, J.H. and BLAU, H.M. (2013). Tumor suppressors: enhancers or suppressors of regeneration? Development 140: 2502-2512.

POSS, K.D., SHEN, J. and KEATING, M.T. (2000). Induction of lef1 during zebrafish fin regeneration. Dev Dyn 219: 282-286.

REGINELLI, A.D., WANG, Y.Q., SASSOON, D. and MUNEOKA, K. (1995). Digit tip regeneration correlates with regions of Msx1 ( Hox 7) expression in fetal and newborn mice. Development 121: 1065-1076.

REICHMAN, O.J. (1984). Evolution of Regeneration Capabilities. Am. Naturalist 123: $752-763$

RIDDLE, R.D., ENSINI, M., NELSON, C., TSUCHIDA, T., JESSELL, T.M. and TABIN, 
C. (1995). Induction of the LIM homeobox gene Lmx1 by WNT7a establishes dorsoventral pattern in the vertebrate limb. Cell 83: 631-640.

RIDDLE, R.D., JOHNSON, R.L., LAUFER, E. and TABIN, C. (1993). Sonic hedgehog mediates the polarizing activity of the ZPA. Cell 75: 1401-1416.

RINKEVICH, Y., LINDAU, P., UENO, H., LONGAKER, M.T. and WEISSMAN, I.L. (2011). Germ-layer and lineage-restricted stem/progenitors regenerate the mouse digit tip. Nature 476: 409-413.

RINKEVICH, Y., MONTORO, D.T., MUHONEN, E., WALMSLEY, G.G., LO, D., HASEGAWA, M., JANUSZYK, M., CONNOLLY, A.J., WEISSMAN, I.L. and LONGAKER, M.T. (2014). Clonal analysis reveals nerve-dependent and independent roles on mammalian hind limb tissue maintenance and regeneration. Proc Natl Acad Sci USA 111: 9846-9851.

RODGERS, J.T., KING, K.Y., BRETT, J.O., CROMIE, M.J., CHARVILLE, G.W., MAGUIRE, K.K., BRUNSON, C., MASTEY, N., LIU, L., TSAI, C.R. et al., (2014). mTORC1 controls the adaptive transition of quiescent stem cells from $G(0)$ to G(Alert). Nature 510: 393-396.

RODGERS, J.T., SCHROEDER, M.D., MA, C. and RANDO, T.A. (2017). HGFA Is an Injury-Regulated Systemic Factor that Induces the Transition of Stem Cells into GAlert. Cell Rep 19: 479-486.

RODRIGUEZ-ESTEBAN, C., SCHWABE, J.W., PENA, J.D., RINCON-LIMAS, D.E., MAGALLON, J., BOTAS, J. and IZPISUA BELMONTE, J.C. (1998). Lhx2, a vertebrate homologue of apterous, regulates vertebrate limb outgrowth. Development 125: 3925-3934.

ROY, S. and GARDINER, D.M. (2002). Cyclopamine induces digit loss in regenerating axolotl limbs. J Exp Zool 293: 186-190.

ROY, S., GARDINER, D.M. and BRYANT, S.V. (2000). Vaccinia as a tool for functional analysis in regenerating limbs: ectopic expression of Shh. Dev Biol218: 199-205.

SAMMARCO, M.C., SIMKIN, J., FASSLER, D., CAMMACK, A.J., WILSON, A., VAN METER, K. and MUNEOKA, K. (2014). Endogenous bone regeneration is dependent upon a dynamic oxygen event. J. Bone Min. Res. 29: 2336-2345.

SANDOVAL-GUZMAN, T., WANG, H., KHATTAK, S., SCHUEZ, M., ROENSCH, K., NACU, E., TAZAKI, A., JOVEN, A., TANAKA, E.M. and SIMON, A. (2014). Fundamental differences in dedifferentiation and stem cell recruitment during skeletal muscle regeneration in two salamander species. Cell Stem Cell 14: 174-187.

SATOH, A., GARDINER, D.M., BRYANT, S.V. and ENDO, T. (2007). Nerve-induced ectopic limb blastemas in the Axolotl are equivalent to amputation-induced blastemas. Dev Biol 312: 231-244.

SAXE, J.P. and LIN, H. (2011). Small Noncoding RNAs in the Germline. Cold Spring Harb Perspect Biol 3.

SCADDING, S.R. and MADEN, M. (1994). Retinoic acid gradients during limb regeneration. Dev Biol 162: 608-617.

SEIFERT, A.W., KIAMA, S.G., SEIFERT, M.G., GOHEEN, J.R., PALMER, T.M. and MADEN, M. (2012). Skin shedding and tissue regeneration in African spiny mice (Acomys). Nature 489: 561-565

SESSIONS, S.K. and BRYANT, S.V. (1988). Evidence that regenerative ability is an intrinsic property of limb cells in Xenopus. J Exp Zool 247: 39-44.

SEYEDHASSANTEHRANI, N., OTSUKA, T., SINGH, S. and GARDINER, D.M. (2017). The Axolotl Limb Regeneration Model as a Discovery Tool for Engineering the Stem Cell Niche. Curr Stem Cell Rep 3: 156-163.

SHIMOMURA, T., KONDO, J., OCHIAI, M., NAKA, D., MIYAZAWA, K., MORIMOTO, Y. and KITAMURA, N. (1993). Activation of the zymogen of hepatocyte growth factor activator by thrombin. J Biol Chem 268: 22927-22932.

SIMKIN, J., SAMMARCO, M.C., DAWSON, L.A., TUCKER, C., TAYLOR, L.J., VAN METER, K. and MUNEOKA, K. (2015). Epidermal closure regulates histolysis during mammalian (Mus) digit regeneration. Regeneration (Oxf) 2: 106-119.

SIMKIN, J., SAMMARCO, M.C., MARRERO, L., DAWSON, L.A., YAN, M., TUCKER, C., CAMMACK, A. and MUNEOKA, K. (2017). Macrophages are required to coordinate mouse digit tip regeneration. Development 144: 3907-3916.

SINGER, M. and CRAVEN, L. (1948). The growth and morphogenesis of the regenerating forelimb of adult Triturus following denervation at various stages of development. J Exp Zool 108: 279-308.

SLACK, J.M. (2006). Amphibian muscle regeneration--dedifferentiation or satellite cells? Trends Cell Biol 16: 273-275.

SPALLANZANI, L. (1769). Prodromo di un opera da imprimersi sopra la riproduzioni animali (An essay on animal reproduction). Mati M. translation. T. Becket and de Hondt, London.

STOCUM, D.L. (1984). The urodele limb regeneration blastema. Determination and organization of the morphogenetic field. Differentiation 27: 13-28.

SUGIURA, T., WANG, H., BARSACCHI, R., SIMON, A. and TANAKA, E.M. (2016) MARCKS-like protein is an initiating molecule in axolotl appendage regeneration. Nature 531: 237-240.

TAKEO, M., CHOU, W.C., SUN, Q., LEE, W., RABBANI, P., LOOMIS, C., TAKETO, M.M. and ITO, M. (2013). Wnt activation in nail epithelium couples nail growth to digit regeneration. Nature 499: 228-232.

TANAKA, E.M. (2016). The Molecular and Cellular Choreography of Appendage Regeneration. Cell 165: 1598-1608.

TANAKA, E.M., DRECHSEL, D.N. and BROCKES, J.P. (1999). Thrombin regulates S-phase re-entry by cultured newt myotubes. Curr Biol 9: 792-799.

TANAKA, E.M., GANN, A.A., GATES, P.B. and BROCKES, J.P. (1997). Newt myotubes reenter the cell cycle by phosphorylation of the retinoblastoma protein. $J$ Cell Biol 136: 155-165

TEDESCO, F.S., DELLAVALLE, A., DIAZ-MANERA, J., MESSINA, G. and COSSU, G. (2010). Repairing skeletal muscle: regenerative potential of skeletal muscle stem cells. J Clin Invest 120: 11-19.

THORNTON, C.S. (1957). The effect of apical cap removal on limb regeneration in Amblystoma larvae. J. Exp. Zool. 134: 357-381.

TSENG, A.S. and LEVIN, M. (2008). Tail regeneration in Xenopus laevis as a mode for understanding tissue repair. J Dent Res 87: 806-816.

TSONIS, P.A. (2000). Regeneration in vertebrates. Dev Biol 221: 273-284.

TWITTY, V.C. and SCHWIND, J.L. (1931). The growth of eyes and limbs transplanted heteroplastically between two species of Amblystoma. J. Exp. Zool. Part A: Ecol. Genetic Physiol. 59: 61-86.

VILLIARD, E., BRINKMANN, H., MOISEEVA, O., MALLETTE, F.A., FERBEYRE, G. and ROY, S. (2007). Urodele p53 tolerates amino acid changes found in p53 variants linked to human cancer. BMC Evol Biol 7: 180

VOGEL, A., RODRIGUEZ, C., WARNKEN, W. and IZPISUABELMONTE, J.C. (1995). Dorsal cell fate specified by chick $L m \times 1$ during vertebrate limb development. Nature 378: 716-720.

WAGNER, I., WANG, H., WEISSERT, P.M., STRAUBE, W.L., SHEVCHENKO, A., GENTZEL, M., BRITO, G., TAZAKI, A., OLIVEIRA, C., SUGIURA, T. et al., (2017). Serum Proteases Potentiate BMP-Induced Cell Cycle Re-entry of Dedifferentiating Muscle Cells during Newt Limb Regeneration. Dev Cell 40: 608-617.e6.

WENEMOSER, D. and REDDIEN, P.W. (2010). Planarian regeneration involves distinct stem cell responses to wounds and tissue absence. Dev Biol 344: 979-991.

YOKOYAMA, H., IDE, H. and TAMURA, K. (2001). FGF-10 stimulates limb regeneration ability in Xenopus laevis. Dev Biol 233: 72-79.

YU, L., HAN, M., YAN, M., LEE, E.C., LEE, J. and MUNEOKA, K. (2010). BMP signaling induces digit regeneration in neonatal mice. Development 137: 551-559.

YUN, M.H. (2015). Changes in Regenerative Capacity through Lifespan. Int J Mol Sci 16: 25392-25432.

YUN, M.H., DAVAAPIL, H. and BROCKES, J.P. (2015). Recurrent turnover of senescent cells during regeneration of a complex structure. eLife 2015;4:e05505 doi: 10.7554/eLife.05505

YUN, M.H., GATES, P.B. and BROCKES, J.P. (2013). Regulation of p53 is critical for vertebrate limb regeneration. Proc Natl Acad Sci USA 110: 17392-17397.

ZENJARI, C., BOILLY, B., HONDERMARCK, H. and BOILLY-MARER, Y. (1997) Nerve-blastema interactions induce fibroblast growth factor-1 release during limb regeneration in Pleurodeles waltl. Dev Growth Differ 39: 15-22.

ZHANG, P. and WAKE, D.B. (2009). Higher-level salamander relationships and divergence dates inferred from complete mitochondrial genomes. Mol Phylogenet Evol 53: 492-508.

ZHAO, W. and NEUFELD, D.A. (1995). Bone regrowth in young mice stimulated by nail organ. J Exp Zool 271: 155-159.

ZHU, W., PAO, G.M., SATOH, A., CUMMINGS, G., MONAGHAN, J.R., HARKINS, T.T., BRYANT, S.V., RANDAL VOSS, S., GARDINER, D.M. and HUNTER, T. (2012). Activation of germline-specific genes is required for limb regeneration in the Mexican axolotl. Dev Biol 370: 42-51. 


\section{Further Related Reading, published previously in the Int. J. Dev. Biol.}

iTRAQ-based proteomic analysis of adaptive response in the regenerating limb of the Cynops orientalis newt Xiao-Fang Geng, Jian-Lin Guo, Xia-Yan Zang, Jing-Yan Sun, Peng-Fei Li, Fu-Chun Zhang and Cun-Shuan Xu Int. J. Dev. Biol. (2015) 59: 487-496

https://doi.org/10.1387/ijdb.150363cx

Proteomics analysis of regenerating amphibian limbs: changes during the onset of regeneration Michael W. King, Anton W. Neff and Anthony L. Mescher

Int. J. Dev. Biol. (2009) 53: 955-969

https://doi.org/10.1387/ijdb.082719mk

\section{Limb muscle development}

Bodo Christ and Beate Brand-Saberi

Int. J. Dev. Biol. (2002) 46: 905-914

http://www.intjdevbiol.com/web/paper/12455628

Vertebrate limb regeneration and the origin of limb stem cells

Susan V Bryant, Tetsuya Endo and David M Gardiner

Int. J. Dev. Biol. (2002) 46: 887-896

http://www.intjdevbiol.com/web/paper/12455626

Retinoic acid and limb regeneration--a personal view

Malcolm Maden

Int. J. Dev. Biol. (2002) 46: 883-886

http://www.intjdevbiol.com/web/paper/12455625

Positional information in vertebrate limb development; an interview with Lewis Wolpert Cheryll Tickle

Int. J. Dev. Biol. (2002) 46: 863-867

http://www.intjdevbiol.com/web/paper/12455621

Treatment of axolotls with retinoids for limb regeneration studies S R Scadding

Int. J. Dev. Biol. (1996) 40: 909-910

http://www.intjdevbiol.com/web/paper/8877467

5 yr ISI Impact Factor $(2016)=2.421$
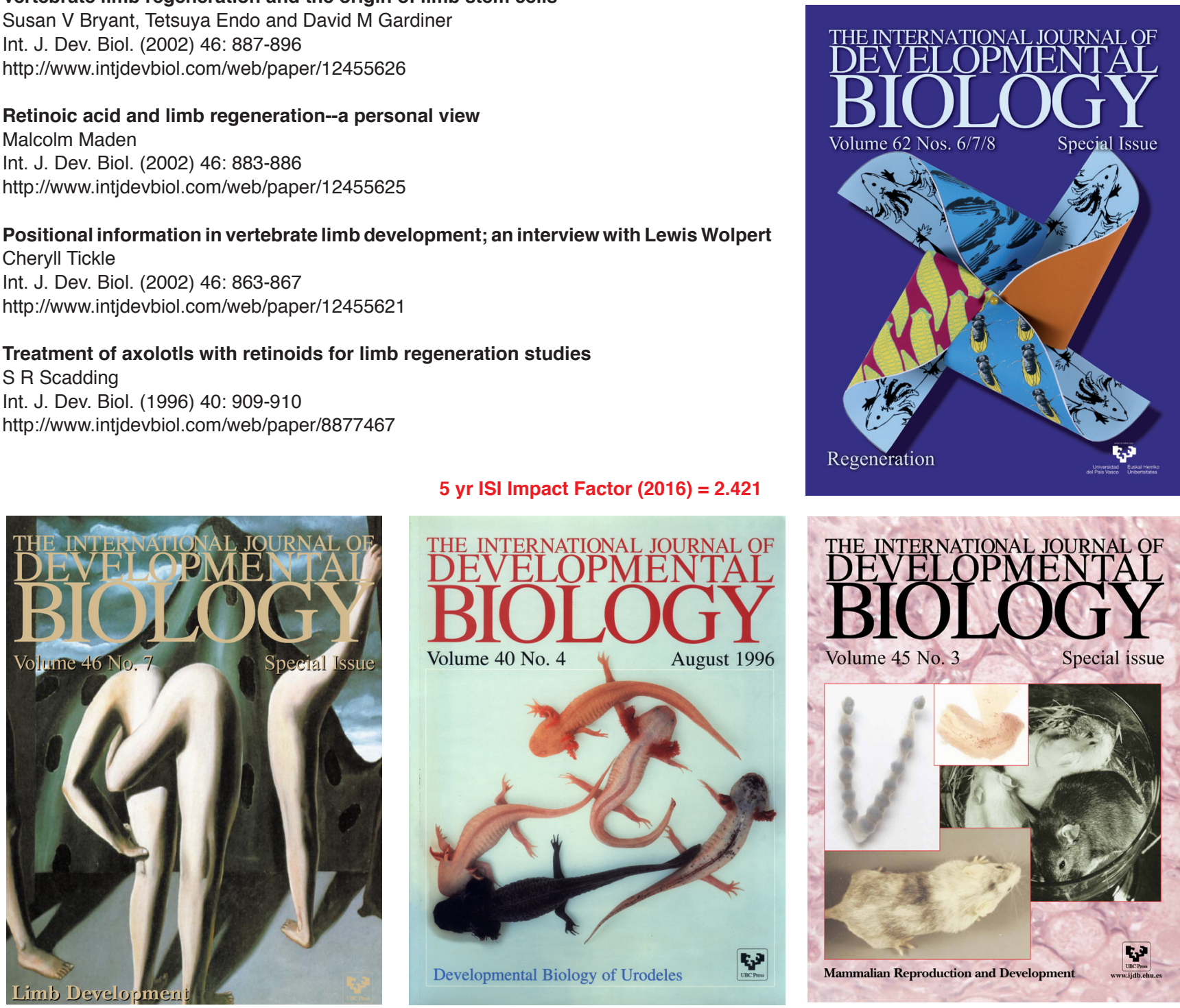